\title{
Immobilized Organo-Mercurial Lyase on Zeolite Using a Solid Binding Peptide
}

\author{
Damien N. McCarthy ${ }^{*}$, Grant C. Edwards \\ Department of Environmental Science, Faculty of Science and Engineering, Macquarie University, Sydney, Australia \\ *Corresponding author: mccarthyd001@gmail.com
}

\begin{abstract}
Methylmercury (MeHg) compounds can form naturally, are highly toxic, and of concern because of their tendency to bio-accumulate. Certain bacteria have evolved mechanisms that can tolerate MeHg by first demethylating $\mathrm{MeHg}$ compounds, before further processing. Drawing inspiration from this demethylation mechanism controlled by a single organo-mercurial lyase in a protonolysis reaction, this research uses a recombinant gene that produces this lyase plus an additional polypeptide that selectively binds to zeolite particles, effectively tethering the enzyme to the solid substrate. This work is part of a broader attempt to create a fixed bed reactor for de-methylation of MeHg. Enzyme immobilization was achieved using a solid binding peptide (SBP) with high affinity for faujasite zeolite (FZ), the choice of binding substrate in the present work. The lyase is coded for by the merB gene, and a sequence with highly conserved active site homology was obtained from E.coli plasmid R8361b. The SBP plus merB sequence was designed such that the SBP was positioned either on the $\mathrm{N}$ or C-terminal of the construct. The DNA was synthesized commercially, and expressed in E.coli (BL21DE3 Star) using pET100® vector. Sanger sequencing was used to confirm construct in transformed cells using standard T7 oligos. Expression was lactose induced, and SDS-PAGE electrophoresis was used to confirm protein production and size. LC-MS/MS and sequence bio-analytics confirmed peptide sequence. Silica binding assays using SDS-PAGE confirmed binding of the enzyme to the silica substrate. Enzyme functionality results using a non-methylated mercuric compound were inconclusive, however the enzyme has not been assessed using MeHg compounds at this stage.
\end{abstract}

Keywords: merB, methylmercury, enzyme immobilization, demthylation

Cite This Article: Damien N. McCarthy, and Grant. C Edwards, "Immobilized Organo-Mercurial Lyase on Zeolite Using a Solid Binding Peptide." International Journal of Environmental Bioremediation \& Biodegradation, vol. 6, no. 1 (2018): 8-17. doi: 10.12691/ijebb-6-1-2.

\section{Introduction}

Methylated mercury species (MeHg) are highly toxic compounds that form mostly via bio-genic mechanisms under certain conditions, particularly anoxic environments with high anionic ligand content [1]. Methylmercury formation is often mediated by microbial activity, in particular by sulfur and iron reducing bacteria (SRB and FeRB respectively), methanogens, and firmicutes [2,3]. The proclivity for such toxic compounds to bio-accumulate in the food web [4], and therefore impact human health, is one of the main factors $\mathrm{MeHg}$ compounds have received much research attention over the past decade. Apart from several transgenic plant studies aimed at bioremediation $[5,6]$, few studies have focused on bio-remediation of $\mathrm{MeHg}$ in aqueous bodies.

One strategy that may prove beneficial in this regard is inspired directly from evolved microbial metabolic mechanisms that deal with $\mathrm{MeHg}$ via de-methylation. Such de-methylating bacteria are ubiquitous and represented by a wide range of taxa [7]. The overall microbial strategy ofen involves the intracellular reduction of $\mathrm{Hg}^{2+}->\mathrm{Hg}^{0}$ by a mercuric reductase enzymatic reaction, whereby $\mathrm{Hg}^{0}$ then naturally volatilizes and passively diffuses from the cell and out of the immediate surrounds into the atmosphere [8]. Where it is necessary for microbes to deal with $\mathrm{MeHg}$, the reduction reaction is preceded by $\mathrm{MeHg}$ intracellular interaction with an organo-mercurial lyase, which cleaves the $\mathrm{C}-\mathrm{Hg}$ bond through a protonolysis reaction [9], producing $\mathrm{CH}_{4}$ and $\mathrm{Hg}^{2+}$, where mercury is then passed to the mercuric reductase enzyme. It appears that the reductase enzyme activates release of the lyase bound $\mathrm{Hg}^{2+}[10]$. The C-Hg enzymatic cleavage confers broad spectrum $\mathrm{Hg}$ resistance. HgR microbes with broad spectrum capabilities are characterized by the presence of the merB gene, which codes for the organo-mercurial lyase.

The mechanistic function of the merB product has not been fully elucidated, however it is highly likely to function as proposed by Parks et.al., [9]. The enzyme itself is relatively small at around $24 \mathrm{kDa}$, having been structurally characterized through crystallography, including various mutants, which have helped deduce the functional domain, key amino residues, and mechanistic architecture $[11,12]$. The may give this enzyme the ability to remain functional while immobilized on an extracellular solid substrate.

Immobilizing technologies greatly reduce the complexity of deploying this bio-catalytic strategy for remediation purposes, as living cells pose problems in terms of delivery to heterogeneous sites, geographical containment 
within the contaminated plume (particularly so in a water column), nutrient supply, and competition from indigenous microbes etc. [13]. The concept explored in this work thus involves the extraction and immobilization of the merB gene product on a solid substrate, that being a faujasite type alumino-silicate zeolite (FZ) in particle form. This work represents the first stage of a broader project such that a fixed bed bio-catalytic reactor may be constructed to de-methylate aqueous MeHg compounds in situ.

Enzyme immobilization techniques often suffer from orientation and target accessibility issues [14]. An approach that may overcome these problems is the use of solid binding peptides (SBP's) that selectively recognize and bind to solid surfaces [15]. The SBP-enzyme conjugate can be either $\mathrm{C}$ or $\mathrm{N}$ terminal, depending on the active site location and orientation required, with the SBP used as a linker to tether the enzyme to the substrate. One such class of SBPs has a high affinity for certain zeolites and can thus be used to immobilize enzymes on silica-based substrates [16]. Zeolite is an ideal substrate for this work due to its inert and robust nature, and because it is readily synthesized and inexpensive. This particular SBP is highly amorphous, overcoming issues with accessibility and steric hindrance, and has been used to immobilize over 25 enzymes on silica based substrates which retained functionality [17]. The immobilization of the enzyme on a silica substrate can be achieved via the expression of a fusion protein that contains this SBP linker and the organo-mercurial lyase, which is then extracted and purified from E.coli cells and bound to solid particles. These particles may then be packed in a column, and it is envisioned that $\mathrm{MeHg}$ concentrations may be reduced or eliminated in aqueous media which interacts with these particles.

\section{Materials and Methods}

\subsection{Recombinant Protein Construct}

Two constructs were designed with the SBP flanking either $\mathrm{N}$ or $\mathrm{C}$ terminal of the merB sequence. The SBP used is a truncated version of one previously described $[17,21]$. merB sequence was derived from GenBank: U77087.1, E.coli plasmid R831b, and codon optimized for expression in E.coli BL21 DE3 Star. Constructs synthesized commercially by GeneArt ${ }^{\circledR}$. Oligos designed as per requirements and synthesized commercially by Life Technologies Corporation. Constructs synthesized in a T7 mediated expression ready pET100® vector with existing $\mathrm{N}$ terminal polyhistidine-tag. These are designated $\mathrm{N}[\mathrm{FZ}] \mathrm{SBP}+$ merB and $\mathrm{C}[\mathrm{FZ}] \mathrm{SBP}+\operatorname{mer} \mathrm{B}$ for $\mathrm{N}$ and $\mathrm{C}$ terminal zeolite binding SBP position respectively. E.coli DH5 $\alpha$ (Life Technologies Corporation) cells as stock held in $20 \%$ glycerol at $-80^{\circ} \mathrm{C}$. Expression was carried out using E.coli BL21 DE3 Star cells (Life Technologies Corporation). The SBP linker amino acid sequence is (VKTQATSREEPPRLPSKHRPG) 3 VKTQTAS.

\subsection{Transformation and DNA Confirmation}

Chemically competent E.coli DH5 $\alpha$ and BL21 DE3 Star cells transformed using heat shock method. S.O.C. media by Thermo Fischer (Cat No. 15544034). Incubation at $37^{\circ} \mathrm{C}$ (shaking at $120 \mathrm{rpm}$ ) with $100 \mu \mathrm{g} / \mathrm{mL}$ Ampicillin (Amp) (Thermo Fischer Cat No. 11593027) doped media. Sanger sequencing was performed by University of Nevada, Reno, at the Nevada Genomics Centre (NGC), using approximately 500ng plasmid template to $10 \mathrm{Pmol}$ primer. Plasmid extraction using Qiagen QIAprep ${ }^{\circledR}$ Spin Miniprep Kit (Cat No. 27104). Oligos supplied by NGC (Fwd): T7 primer 5' TAATACGACTCACTATAGGG. Pairwise sequence alignment was performed using Emboss Needle (C).

\subsection{Expression and Purification}

Lactose based auto-induction was performed using twostage media. Cells were first grown to stationary phase using RM media plus glucose (per L: $20 \mathrm{~g}$ casamino acids, 100mL 10x M9 salts, $1 \mathrm{~mL} 1 \mathrm{M} \mathrm{MgCl}_{2}, 10 \mathrm{~mL}$ glucose, Amp to $1 \mathrm{mM}$ in $\mathrm{dH}_{2} \mathrm{O}$ ) at $37^{\circ} \mathrm{C}$ with shaking at $120 \mathrm{rpm}$. Glucose ensures leaky $\mathrm{T} 7$ promoter induction can be tightly controlled, and was monitored regularly to ensure supply using glucose assays (Genzyme Diagnostics Glucose [Trinder] Assay Cat No. 22032). ZYM-5052 Media ((per L: 2 mL 1M MgSO 4 , 40mL 25x M Sola (per L: 88.75g $\mathrm{NaHPO}_{4}$, 85g $\mathrm{KH}_{2} \mathrm{PO}_{4}, 67 \mathrm{~g} \mathrm{NH} \mathrm{NH}_{4} \mathrm{Cl}$, 17.75g $\mathrm{Na}_{2} \mathrm{SO}_{4}$ ), $2 \mathrm{~g}$ lactose, $5 \mathrm{~mL} 100 \%$ glycerol, $0.5 \mathrm{~g}$ glucose)) was inoculated to $\mathrm{OD}_{600} \approx 0.5$ with $\mathrm{RM}$ media stationary phase cells. Protein expression quantified using Thermo Fischer $\mathrm{EZQ}^{\mathrm{TM}}$ Protein Quantification Kit Cat No. R33200. Non induced cells, and cells containing neither $\mathrm{N}[\mathrm{FZ}] \mathrm{SBP}+$ merB or $\mathrm{C}[\mathrm{FZ}] \mathrm{SBP}+$ merB as controls. $500 \mu \mathrm{L}$ aliquots were removed at various time-points, pelleted $\left(7 \times 10^{3} \mathrm{rpm}^{-\min } \times 2 \mathrm{mins}\right)$, boiled in $80 \mu \mathrm{L} 2 \mathrm{x}$ SDS at $97^{\circ} \mathrm{C}$ for $7 \mathrm{mins}$, centrifuged ( $7 \times 10^{3} \mathrm{rpm}^{- \text {min }}$ for 3 mins), and protein expression checked (for size) using $10 \mu \mathrm{L}$ soluble product on (NuPAGE тм 12\% Bis-Tris) protein gels (1X MOPS/SDS) at $120 \mathrm{~V}$, followed by Coomassie Blue ${ }^{\mathrm{TM}}$ staining. Pelleted samples were stored at $-20^{\circ} \mathrm{C}$ where necessary.

Protein purified using Ni-NTA agarose (Invitrogen, Cat. No. R901-01) by gravity fed column (Bio-Rad PolyPrep ${ }^{\circledR}$ chromatography column (Cat. 731-1550). Binding buffer (20mM Tris, 500mM NaCl, 10mM Imidizole, 10\% glycerol, pH 8.0). Wash buffer (20mM Tris, $100 \mathrm{mM} \mathrm{NaCl}$, $30 \mathrm{mM}$ Imidizole, $\mathrm{pH}$ 8.0. Elution buffer (20mM Tris, $100 \mathrm{mM} \mathrm{NaCl}, 300 \mathrm{mM}$ Imidizole, $\mathrm{pH}$ 8.0) Synthesis of the desired amino sequence(s) was $100 \%$ confirmed by tandem mass spectrometry after trypsin digestion of excised polyacrylamide gel bands. LC-MS/MS was performed by the Nevada Proteomics Centre at the University of Nevada, Reno, using an LC gradient of 6090 min with data analysis performed using Scaffold Version 4.8 .4 with peptide threshold of $80 \%$ and protein (min 2) threshold of $99 \%$.

\subsection{Zeolite Binding Assay}

Post purification, the enzyme was mixed with silica particles (SiliaFlash ${ }^{\circledR}$ Irregular Silica Gels, 60^ (Cat No. R12030B); Zeolite Y CBV100, Zeolyst Int; Sigma-

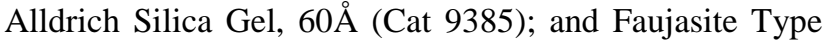
Zeolite, Sigma-Aldrich (BCR704-10G)). The binding assay is described by Sunna et. al. (2013). Briefly, approximately $100 \mathrm{mg}$ particles are first vortexed in $1 \mathrm{ml}$ 
wash buffer (10 mM Tris-HCl, pH 7.5, 100mM NaCl and $1 \%$ Triton-X100), repeated twice, and dried under $\mathrm{N}_{2}$. Soluble protein was mixed with particles and incubated by slow rotation at room temperature for $1 \mathrm{~h}$. Any unbound fraction was removed after centrifugation at $10 \times 10^{3} \mathrm{rpm}$ for 30s. The residual silica pellet was washed by vortexing with $100 \mu \mathrm{l}$ of $100 \mathrm{mM}$ Tris-HCl buffer, $\mathrm{pH}$ 8.0. Washing was repeated twice and wash fraction samples retained. Bound protein was eluted using $100 \mu \mathrm{l}$ of $2 \mathrm{x}$ SDS PAGE-loading buffer followed by incubation at $99^{\circ} \mathrm{C}$ for $10 \mathrm{~m}$. Pellet was vortexed briefly every $2 \mathrm{~m}$ during this elution step. The various fractions were analyzed using SDS-PAGE with Coomassie Blue ${ }^{\mathrm{TM}}$ staining.

\subsection{Functional Assay}

Functionality was assessed using an indirect assay on $250 \mathrm{~mL}$ culture. Cells were pelleted $(5 \mathrm{krpm} 15 \mathrm{mins}$ at $4^{\circ} \mathrm{C}$ ), resuspended and briefly washed in lysis buffer (50mM Tris-HCl (pH 7.5), 1mM $\beta$-mercaptoethanol, $1 \mathrm{mM}$ PMSF, 0.5mM EDTA, $5 \%{ }^{\mathrm{v} / \mathrm{v}}$ glycerol) before centrifugation (5krpm $15 \mathrm{mins}$ at $4^{\circ} \mathrm{C}$ ). Cells were resuspended in $2 \mathrm{~mL}$ lysis buffer and sonicated on ice for $15 \mathrm{~s}$. The mixture was centrifuged (15krpm $10 \mathrm{mins}$ at $\left.4^{\circ} \mathrm{C}\right)$ and $20 \mu \mathrm{L}$ soluble fraction added to assay solution (50mM Tris- $\mathrm{HCl}(\mathrm{pH} 7.5)$, 1mM L-Cys, 1 $\mu \mathrm{M}$ 4-Chloromercuribenzoic acid (PCMB)) and absorbance at $\lambda_{250}$ monitored every minute for 20 mins. Crude extract and FZ bound enzyme were tested.

\section{Results and Discussion}

\subsection{Protein Expression}

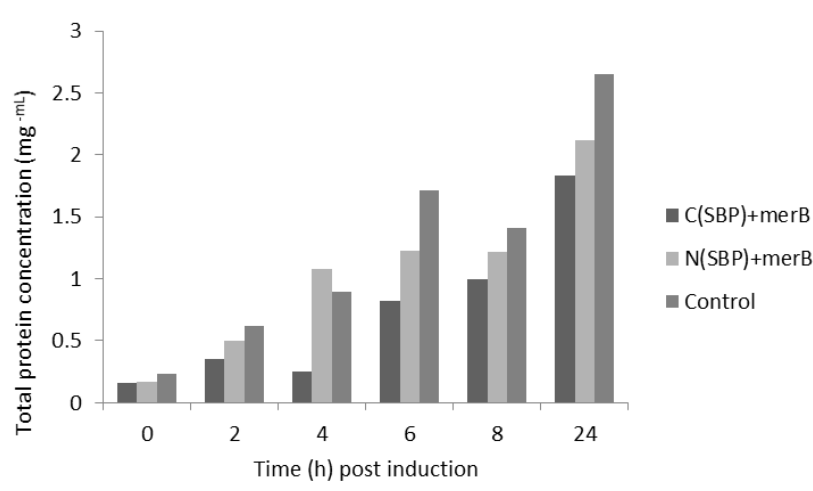

Figure 1. Average total protein expression $\left(\mathrm{mg}^{-\mathrm{mL}}\right)$ over time where $\mathrm{T}_{0}$ is $\mathrm{OD}_{600}=0.5$ for $\mathrm{C}[\mathrm{FZ}] \mathrm{SBP}+$ merB and $\mathrm{N}[\mathrm{FZ}] \mathrm{SBP}+$ merB transformants (control was IDOLDH+)

Protein expression was first unsuccessfully attempted using IPTG, where it was noted that growth rates and viability were so variable after induction at $\mathrm{OD}_{600}=0.4$ 0.6 at varying concentrations between 0.1 and $2.0 \mu \mathrm{M}$ final concentration IPTG that data sets could not be replicated. There is evidence that elevated levels of merB product can be toxic, somewhat modulated by inclusion body formation [18]. Although the expected product is soluble, the insoluble fraction was also analyzed but no evidence was obtained for the expected product in this fraction. The T7 promoter used in this plasmid (pET100®) is known to be somewhat leaky [19], and to rule out toxicity problems that may be occurring, we used a glucose and lactose based induction method to tightly control expression, which proved much more successful.

Using total protein concentration as a proxy for growth rates, post induction batches were monitored every $2 \mathrm{~h}$ for 8hrs, then sampled again at 24h. Figure 1., shows total soluble protein content after expression was induced using the glucose-lactose induction method. This result is much more in line with expectations, although of note is that the $\mathrm{C}[\mathrm{FZ}] \mathrm{SBP}+$ merB variant consistently does not seem to do as well, and in particular struggles consistently between 3 and $4 \mathrm{~h}$ mark post induction. No attempt was made to solve that puzzle, although there is some evidence that $\mathrm{C}$ terminal additions to constructs are more difficult to express successfully [20]. Conversely, between 3 and $4 \mathrm{~h}$ post induction appears to be the time with the highest growth rate for $\mathrm{N}[\mathrm{FZ}] \mathrm{SBP}+$ merB. Induction time was always at or adjusted to the same cell density so this cannot explain this variable. In any case, cells with $\mathrm{N}$ terminal construct performed consistently better using lactose based induction, and although $\mathrm{C}[\mathrm{FZ}] \mathrm{SBP}+$ merB cells did eventually grow at a comparable rate, they took additional time to recover post induction and appear to have suffered some considerable viability issues as well.

SDS-PAGE was used to help detect soluble protein fraction. Figure 2, is an image of the Coomassie Blue ${ }^{\mathrm{TM}}$ stained SDS-PAGE gel, indicating products of the expected MW of approximately 34.8kDa. Lane 14 is overspill and can be ignored. The induced bands are clearly not visible $2 \mathrm{~h}$ post induction and we surmise this is due to residual glucose availability, thus repressing expression. Controls were both IPTG induced at $\mathrm{OD}_{600}=0.5$ and these gel fractions represent $8 \mathrm{~h}$ post induction.

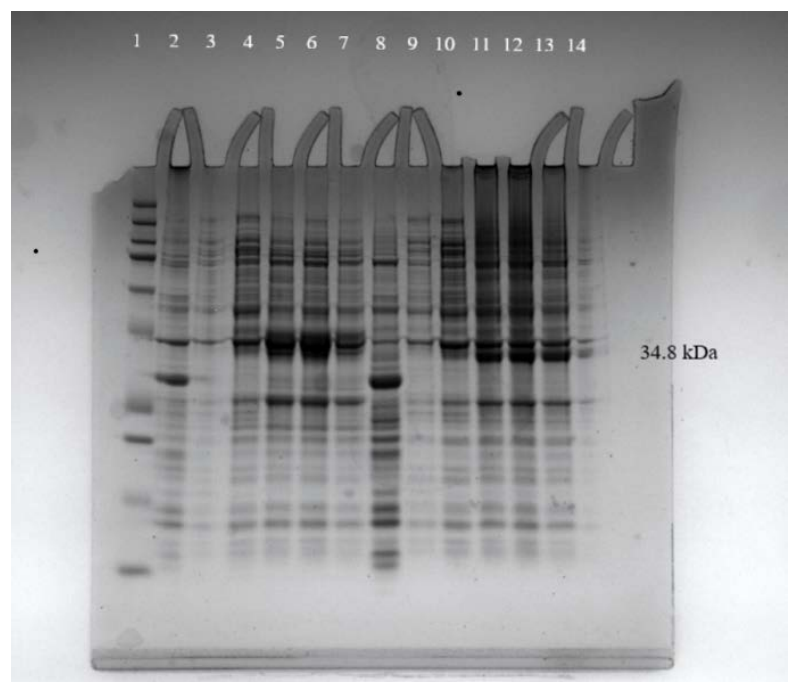

Figure 2. SDS-PAGE gel indicating product at the expected MW of 34.8 $\mathrm{kDa}$ for both $\mathrm{C}$ and $\mathrm{N}(\mathrm{SBP})+$ merB constructs. Lane 1 is Bio-Rad protein ladder, Lane 2 is pUC19 control, Lanes 3-7 are C(SBP)+merB 2,4,6,8 and 24h post induction (respectively), Lane 8 is IDOLDH(+) control, and Lanes 9-13 are $\mathrm{N}(\mathrm{SBP})+$ merB 2,4,6,8 and $24 \mathrm{~h}$ post induction (respectively). Lane 14 is overspill and should be ignored

In order to confirm $\mathrm{N}[\mathrm{FZ}] \mathrm{SBP}+$ merB growth, cells were again grown until $8 \mathrm{~h}$ post induction, this time using auto induction method only. As is clearly visible in Figure 3, the $\mathrm{N}$ terminal variant successfully grew, and the time series clearly indicates any toxicity issues seem to have been mitigated as progressively more protein is found in the soluble fraction as growing time is extended. 
The wells were each loaded with $10 \mu \mathrm{L}$ sample ruling out inconsistent volumes, indicating the sample was progressively more concentrated with the desired product.

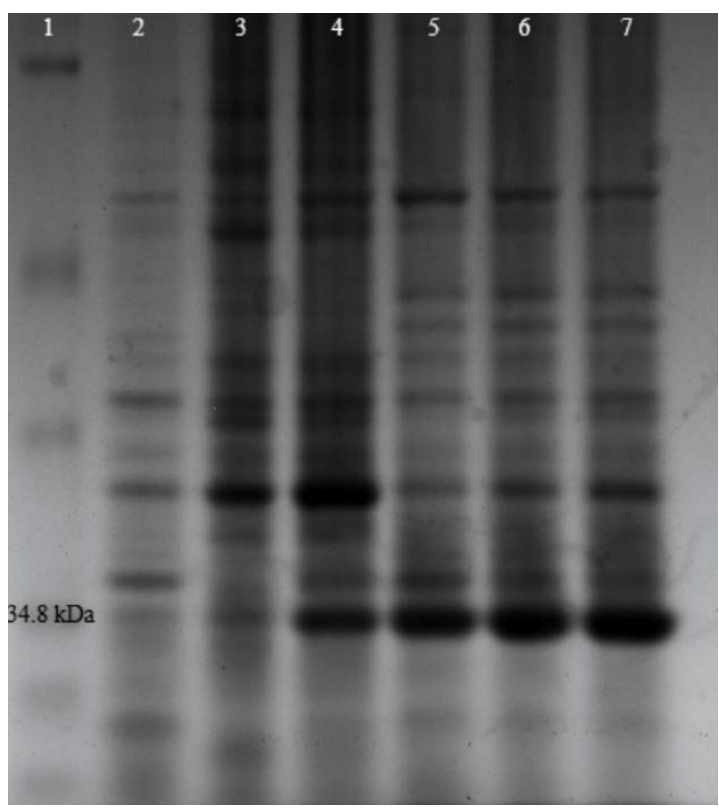

Figure 3. SDS-PAGE gel image of N[FZ]SBP+merB using auto induction media Lane 1. Bio-Rad Broad Spectrum protein ladder, Lane 2. Non-induced, Lane 3. 0.5 OD600, Lane 4. 2h post induction, Lane 5. 4h post induction, Lane 6. $6 \mathrm{~h}$ post induction, Lane 7 . 8h post induction

\subsection{Sequencing}

Cloning confirmation of the desired construct was obtained using Sanger Sequencing, and expression was confirmed using LC-MS/MS after trypsin digestion (data in supplementary). The results for $\mathrm{C}$ terminal variant were not in line with predicted results for either. In particular, $\mathrm{C}[\mathrm{FZ}] \mathrm{SBP}+$ merB variant mass spectrometry results were poor. There was no match for a peptide adjacent to the $\mathrm{C}$ term although one was predicted. MS results for $\mathrm{N}[\mathrm{FZ}] \mathrm{SBP}+$ merB were more conclusive, showing 8 peptide matches representing 80aa's with over 25\% coverage, including coverage of the SBP conjugate. Due to the many problems associated with the $\mathrm{C}$ terminal variant it is likely the $\mathrm{N}$ terminal variant would be easier to scale up production.

The SBP has an amorphous structure which can assist with enzyme orientation and steric hindrance issues. This structure was confirmed theoretically using the Foldindex ( [22] software to ascertain whether the $\mathrm{N}$ terminal SBP segment of the polypeptide conjugate is folded as opposed to the functional merB derived segment. Figure 4 clearly indicates the amino sequence containing the SBP is predicted to be unfolded.

This amorphous structure is important because when tethering enzymes to solid substrates, maximum flexibility is required to ensure the target molecule, in this case methylmercury, is not hindered from interacting with the functional domain of the enzyme. The SBP structure allows for greater degrees of freedom to as opposed to direct binding on solid substrates.

As sequencing data indicated successful production of the enzyme with SBP for the N[FZ]SBP+merB variant, a series of silica/zeolite binding assays were performed.

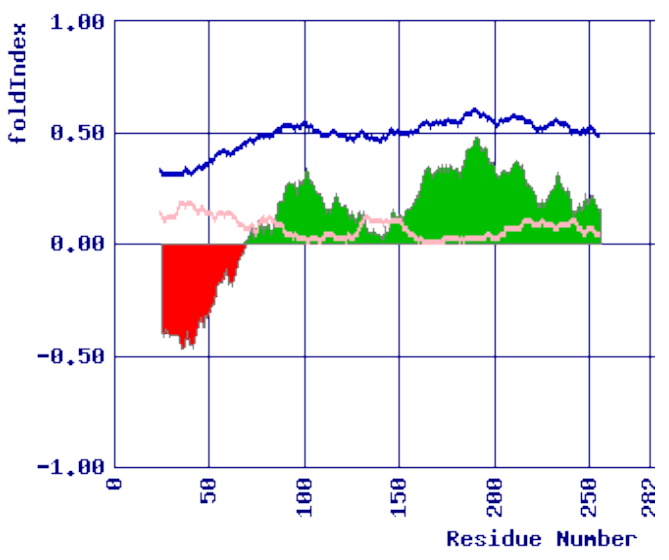

folded unfolded - Phobic - Charge

Figure 4. Foldindex@ prediction for intrinsically unfolded segment of the $\mathrm{N}[\mathrm{FZ}] \mathrm{SBP}+$ merB variant, indicating the SBP segment is intrinsically unfolded.

\subsection{Binding Assays}

Solid binding peptides are a valuable tool for recombinant production of immobilized enzymes. The particular SBP used in the current approach is known to have a very high selective affinity for FZ, affording it great potential for use in a variety of contexts [21]. To evaluate the binding of our products to silica and zeolites, a binding assay was performed. Although the binding mechanism has not been fully elucidated, to assess the robustness of the N[FZ\}SBP +merB:FZ conjugate, particle bound enzyme were subjected to repeated washing by 30s vortexing in wash buffer and the wash fractions analyzed for unbound enzyme.

As some native E.coli proteins are known to bind to silica, both $\mathrm{N}$ and $\mathrm{C}$ terminal products were purified by HIS-tag and exchange buffer treatments prior to binding. To ensure purity, silica and zeolite particles were prewashed in wash buffer and dried under $\mathrm{N}_{2}$. No enzyme was detected for the $\mathrm{C}[\mathrm{FZ}] \mathrm{SBP}+$ mer $B$ variant after purification. This was not surprising given the lack of detection of the SBP conjugate with MS/MS, troublesome growth issues, and poorly resolved MW data for this variant. Considering the ongoing issues with the $\mathrm{C}$ terminal variant, we decided to concentrate on $\mathrm{N}[\mathrm{FZ}] \mathrm{SBP}+$ merB, and all following results are based on that construct.

Our initial use of $60 \AA$ silicas and CBV100 showed low or no binding capacity which was expected and is in line with previous research [17,21]. Type Y faujasite zeolite is known to have greater binding capacity for this SBP. Figure 5 and Figure 6 tend to support that notion. Further, we have used a truncated version of the SBP where only 3 repeats of the given amino sequence were used instead of the four used by Nygard et.al., (2002) in their initial work. This was proposed by Sunna et.al., (2013) and seems to be confirmed by our results.

Figure 6 indicates that the N[FZ]SBP+merB variant was successfully bound to FZ type zeolite. The unbound fraction in lane 2 is likely due to loading issues where too much enzyme was mixed with particles and maximum binding capacity was breached. No attempt was taken to optimize binding amounts, but this would obviously be required in scale up. Similarly, the first two wash fractions indicate loss of enzyme, and we surmise this is due to overloading because, by wash 3 fraction, there is little or no enzyme 
coming off. The eluted fraction clearly shows that the enzyme had previously been successfully bound to the FZ type zeolite, and so the fact there was no enzyme in the third wash fraction indicates what was bound was bound strongly.

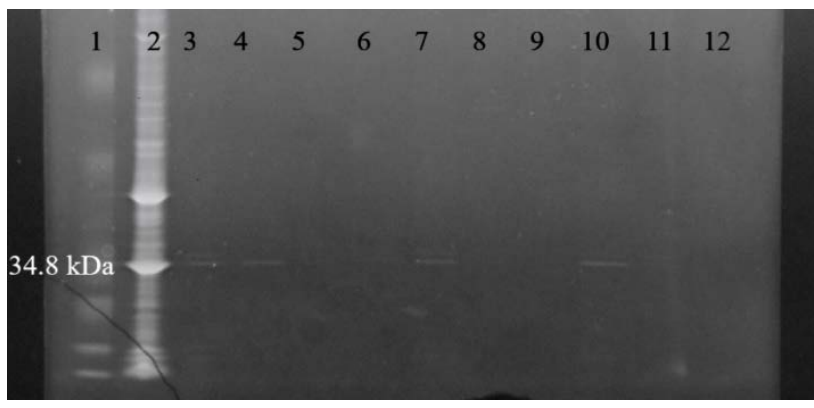

Figure 5. SDS-PAGE gel indicating SBP does not bind to Siliaflash or Sigma-Aldrich $60 \AA$ silica gel, or CBV100 zeolite. Lane 1. Ladder (Bio-rad broad range), Lane2. Crude extract, Lane 3. Ni purified, Lane 4. Unbound on Sigma-Aldrich gel, Lane 5. Combined wash fractions for previous, Lane 6. Eluted fraction, Lane 7. Unbound on CBV100 zeolite, Lane 8. Combined wash fractions for previous, Lane 9. Eluted fraction, Lane 10. Siliaflash gel unbound, Lane 11. Combined wash fractions for previous, Lane 12, Eluted fraction

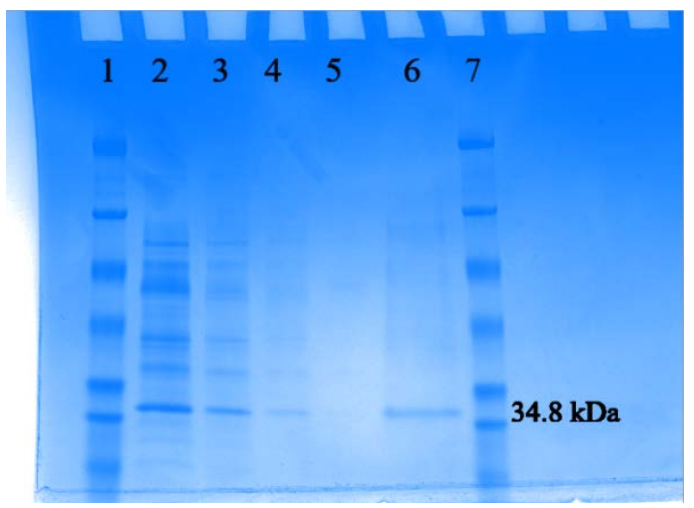

Figure 6. SDS-PAGE gel indicating SBP binds to Type Y Faujasite zeolite. Lane 1. Ladder (Bio-rad), Lane2. Unbound fraction, Lane 3. Wash fraction 1, Lane 4. Wash fraction 2, Lane 5. Wash fraction 3, Lane 6. Eluted fraction showing enzyme was bound, Lane 7. Repeated ladder

Our attempts to assess functionality of the enzyme were not conclusive at this stage. In particular, we are yet to quantify enzymatic activity using methylmercury compounds. In previous work by the author (unpublished) the companion merA gene was designed and bound to silica in a similar fashion. There was evidence of retained functionality in that case. One issue with the merA enzymatic reaction is that it requires $\mathrm{NADPH}^{+}$as a co-factor, making the functionality more difficult and expensive to replicate while the enzyme was immobilized on a solid substrate. However if a suitable co-factor analog can be found then this technology may be more practical. One can envision a co-localised merA;merB set up where both enzymes could be bound to the same particle providing two stage catalysis resulting in not only degradation but removal of $\mathrm{MeHg}$ from contaminated waters.

\section{Conclusion}

Successful expression and binding to a solid zeolite substrate for this novel recombinant enzyme paves the way for a methyl mercury filter to be designed and employed to remediate contaminated waters by degrading the compound to its much less toxic form. The benefits of binding with an amorphous peptide linker are that it offers advantages over other traditional binding methods in terms of orientation and steric hindrance problems that are often encountered. Even though we were unable at this stage to show the merB derived lyase enzyme remained functional while bound, this technique has been used to bind enzymes that remained functional. Difficulties with the highly toxic nature of methylmercury precluded any further optimization at this preliminary stage. The method used in this work seems to be promising in that both mer $B$ and merA (unpublished) have now been bound to silica nanoparticles using this method, More research is required to address how to implement an efficient and cost effective way to degrade and remove $\mathrm{MeHg}$ from aqueous environments.

\section{Acknowledgements}

The authors wish to thank Christie Howard, PhD, and Brandon Purdy of University of Nevada, Reno (UNR) for their generous assistance with this work and Assoc. Dean David Shintani, Biotechnology and Natural Resources, UNR, for logistical support. Funding for this work was provided by the Australian Government Research Training Program (RTP), and Macquarie University, NSW, Australia (HDR funding initiative).

\section{Competing Interests Statement}

The authors whose names are listed on this manuscript certify that they have NO affiliations with or involvement in any organization or entity with any financial or nonfinancial interest in the subject matter or materials discussed in this manuscript, and that there are no conflicts of interest to disclose.

\section{Abbreviations}

$\mathrm{Hg}=$ mercury; MeHg = methylated mercury; SRB = sulfur reducing bacteria; FeRB = iron reducing bacteria; SBP = solid binding peptide; HgR = mercury resistant microbes; $\mathrm{OD}_{600}=$ optical density at $\lambda 600 \mathrm{~nm}, \mathrm{FZ}=$ faujasite type zeolite.

\section{References}

[1] Frohne, T., Rinklebe, J., Langer, U., Du Laing, G., Mothes, S. and Wennrich, R., 2012. Biogeochemical factors affecting mercury methylation rate in two contaminated floodplain soils. Biogeosciences, 9(1), pp.493-507.

[2] Gilmour, C.C., Henry, E.A. and Mitchell, R., 1992. Sulfate stimulation of mercury methylation in freshwater sediments. Environmental Science \& Technology, 26(11), pp.2281-2287.

[3] Kerin, E.J., Gilmour, C.C., Roden, E., Suzuki, M.T., Coates, J.D. and Mason, R.P., 2006. Mercury methylation by dissimilatory iron-reducing bacteria. Applied and environmental microbiology, 72(12), pp.7919-7921. 
[4] Morel, F.M., Kraepiel, A.M. and Amyot, M., 1998. The chemical cycle and bioaccumulation of mercury. Annual review of ecology and systematics, pp.543-566.

[5] Lyyra, S., Meagher, R.B., Kim, T., Heaton, A., Montello, P., Balish, R.S. and Merkle, S.A., 2007. Coupling two mercury resistance genes in Eastern cottonwood enhances the processing of organomercury. Plant biotechnology journal, 5(2), pp.254-262.

[6] Basak, B. and Dey, A., 2015. Bioremediation Approaches for Recalcitrant Pollutants: Potentiality, Successes and Limitation. Toxicity and Waste Management Using Bioremediation, p.178.

[7] Boyd, E. and Barkay, T., 2012. The mercury resistance operon: from an origin in a geothermal environment to an efficient detoxification machine.Frontiers in microbiology, 3, p.349.

[8] Fox, B. and Walsh, C.T., 1982. Mercuric reductase. Purification and characterization of a transposon-encoded flavoprotein containing an oxidation-reduction-active disulfide. Journal of Biological Chemistry, 257(5), pp.2498-2503.

[9] Parks, J.M., Guo, H., Momany, C., Liang, L., Miller, S.M., Summers, A.O. and Smith, J.C., 2009. Mechanism of $\mathrm{Hg}-\mathrm{C}$ Protonolysis in the Organomercurial Lyase MerB. Journal of the American Chemical Society, 131(37), pp.13278-13285.

[10] Silva, P.J. and Rodrigues, V., 2015. Mechanistic pathways of mercury removal from the organomercurial lyase active site. PeerJ, 3, pp 1127.

[11] Lafrance-Vanasse, J., Lefebvre, M., Di Lello, P., Sygusch, J. and Omichinski, J.G., 2009. Crystal structures of the organomercurial lyase merb in its free and mercury-bound forms insights into the mechanism of methylmercury degradation. Journal of Biological Chemistry, 284(2), pp.938-944.

[12] Di Lello, P., Benison, G.C., Valafar, H., Pitts, K.E., Summers, A.O., Legault, P. and Omichinski, J.G., 2004. NMR structural studies reveal a novel protein fold for MerB, the organomercurial lyase involved in the bacterial mercury resistance system. Biochemistry, 43(26), pp.8322-8332.
[13] Boopathy, R., 2000. Factors limiting bioremediation technologies. Bioresource technology, 74(1), pp.63-67.

[14] Wingard, L.B., Katchalski-Katzir, E. and Goldstein, L. eds., 2014.Immobilized enzyme principles: applied biochemistry and bioengineering (Vol. 1). Elsevier.

[15] Care, A., Bergquist, P.L. and Sunna, A., 2015. Solid-binding peptides: smart tools for nanobiotechnology. Trends in biotechnology, 33(5), pp.259-268.

[16] Patwardhan, S.V., Emami, F.S., Berry, R.J., Jones, S.E., Naik, R.R., Deschaume, O., Heinz, H. and Perry, C.C., 2012. Chemistry of aqueous silica nanoparticle surfaces and the mechanism of selective peptide adsorption. Journal of the American Chemical Society, 134(14), pp.6244-6256.

[17] Sunna, A., Chi, F. and Bergquist, P.L., 2013. A linker peptide with high affinity towards silica-containing materials. New biotechnology, 30(5), pp.485-492.

[18] Murtaza, I., Dutt, A. and Ali, A., 2002. Biomolecular Engineering of Escherichia coli Organo-mercurial Lyase Gene and its Expression, Indian Jnl of Biotech, Vol. 1, pp 117-120.

[19] Mertens, N., Remaut, E. and Fiers, W., 1995. Tight transcriptional control mechanism ensures stable high-level expression from T7 promoter-based expression plasmids. Nature Biotechnology, 13(2), pp.175-179.

[20] Waugh, D.S., 2005. Making the most of affinity tags. Trends in biotechnology, 23(6), pp.316-320.

[21] Nygaard, S., Wendelbo, R. and Brown, S., 2002. Surface-specific zeolite-binding proteins. Advanced Materials, 14(24), pp. 18531856.

[22] Prilusky, J., Felder, C.E., Zeev-Ben-Mordehai, T., Rydberg, E.H., Man, O., Beckmann, J.S., Silman, I. and Sussman, J.L., 2005. FoldIndex(): a simple tool to predict whether a given protein sequence is intrinsically unfolded. Bioinformatics, 21(16), pp.3435-3438. 


\section{Supplementary data}

The following are for $\mathrm{N}$ terminal variant only.

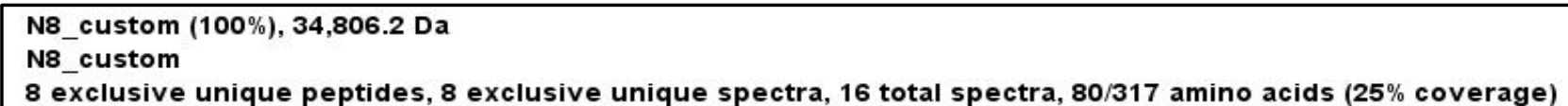

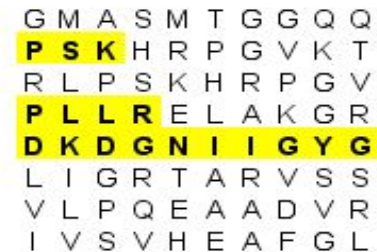

$M G R D L Y D D D D$

QATSR E EPPR

$K T Q T$ A S K L A P

$P \vee S R T$ T L A G I

L T L R E T S Y V F

$H C A$ A T G A P V S

QSF C C H V H F

$G Q E F N R H L L Q$

K D H P F T $\vee$ K T Q

LPSKHRPGVK

$Y$ I L E L L T S VN

L D W P A E R V A A

E I D D R R L Y A W

$L T \vee S P S E I Q A$

$A S \vee P T A E D W A$

TMS S R T P

MS results following trypsin digest as per Scaffold v 4.8.4. Highlighted are peptide matches.

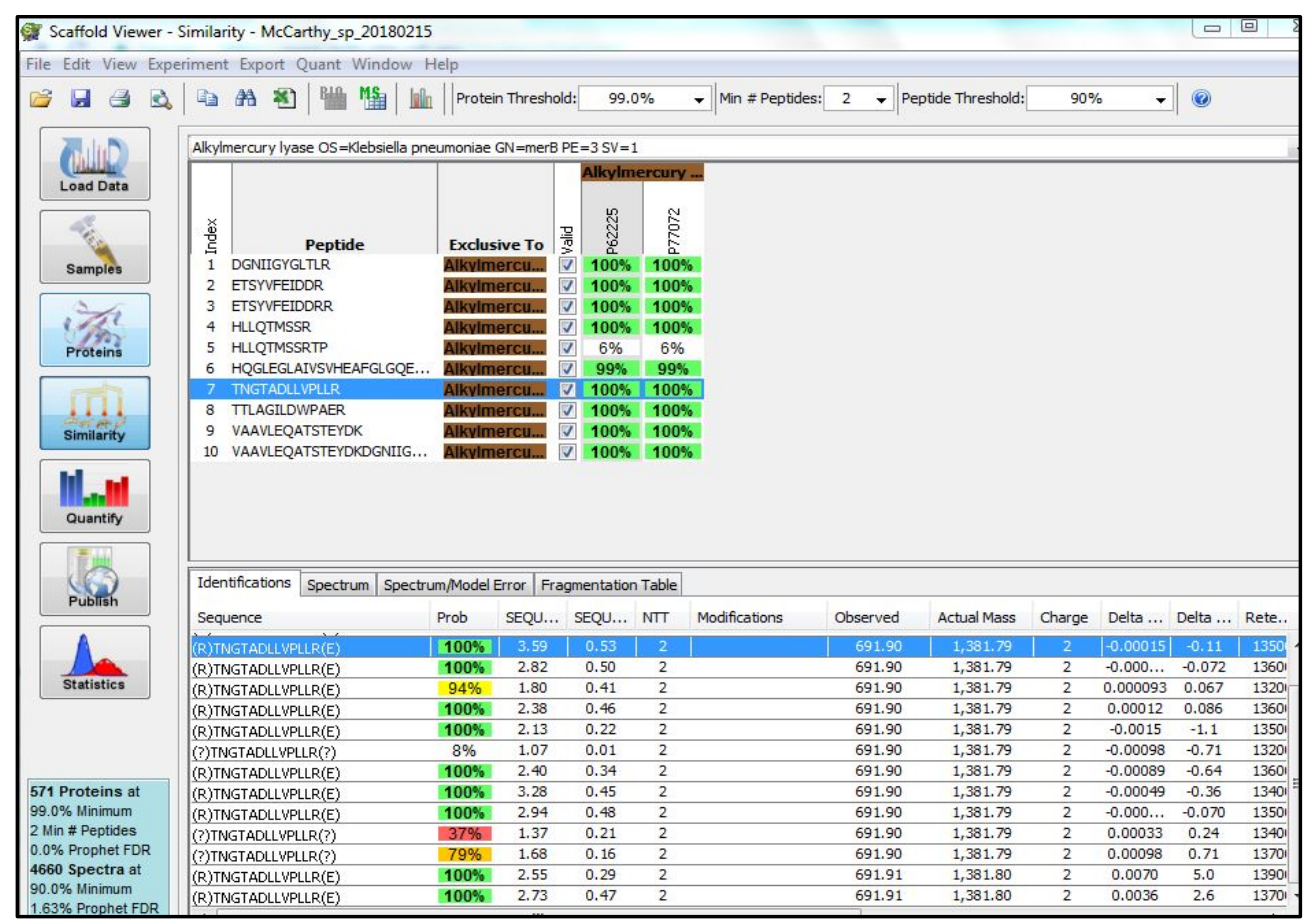

Scaffold output for second expression replicate (gel band excision). 10 unique peptide matches for P77072 (alkyl organomercurial lyase)

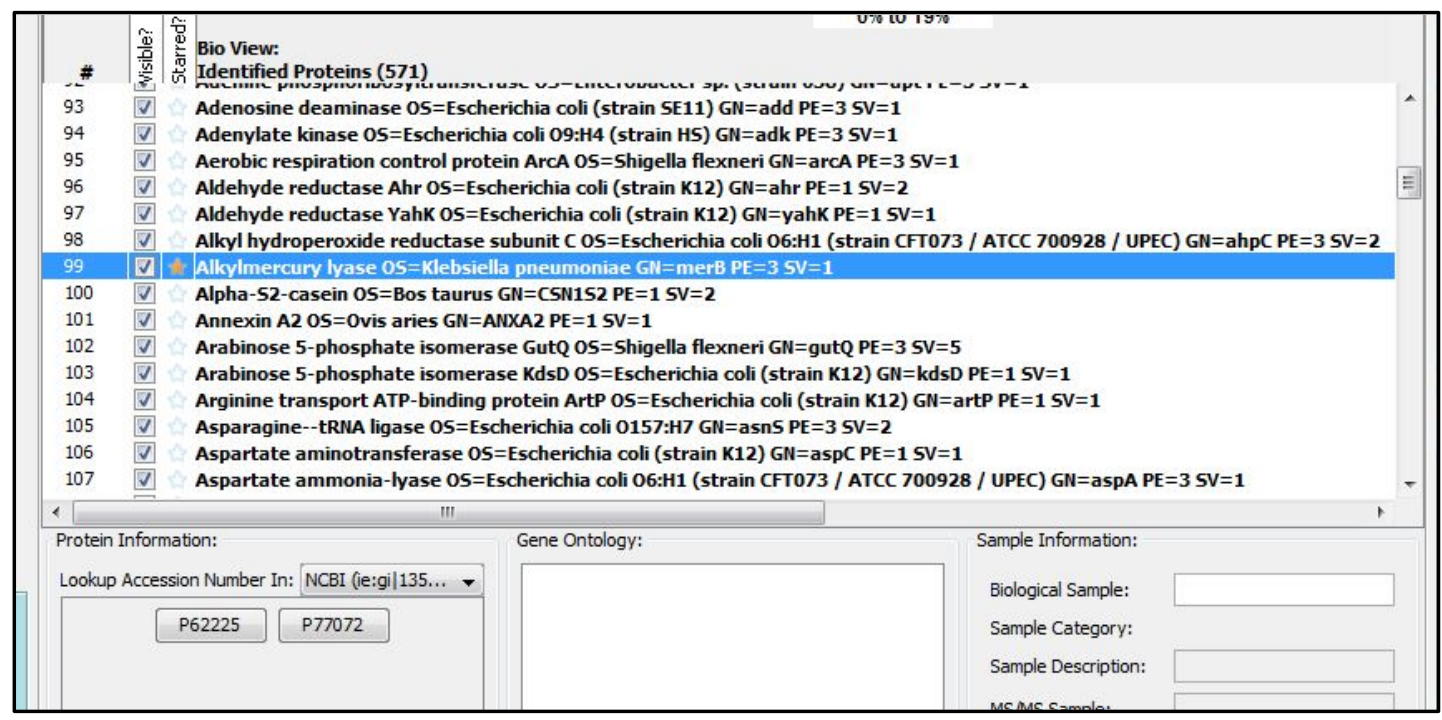


Scaffold output second replicate expression (gel excision) - mass spec results.

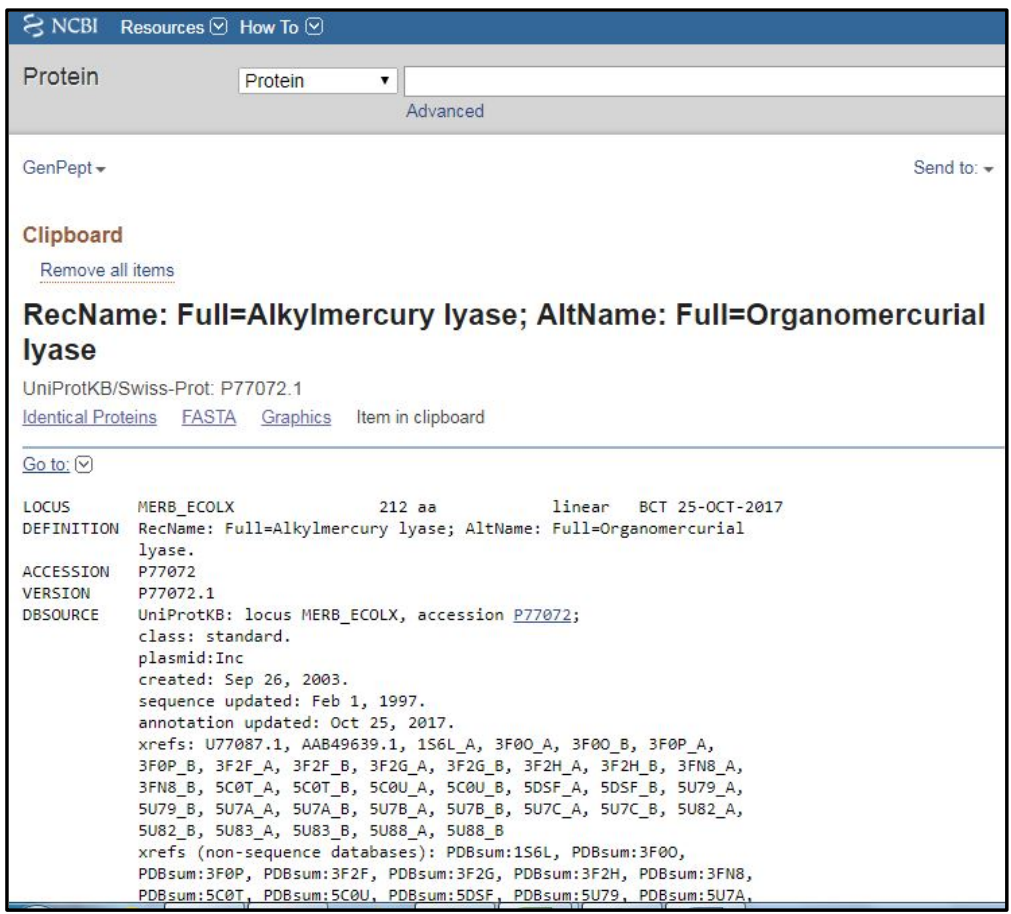

NCBI search results on accession number P77072

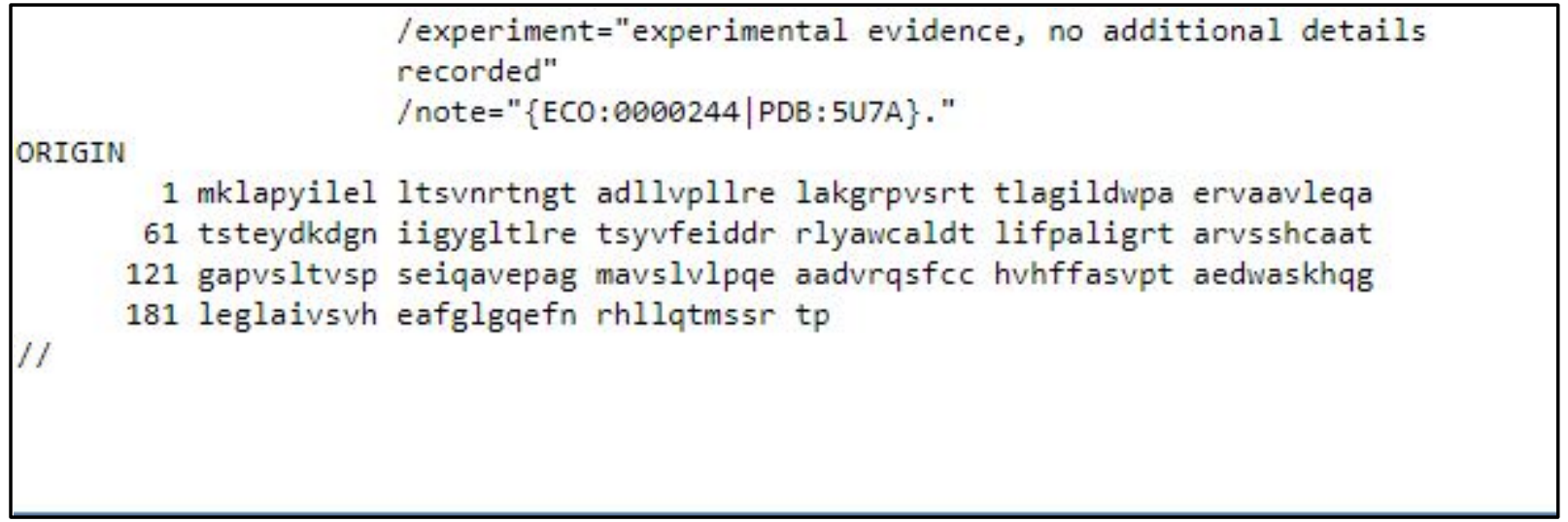

NCBI sequence confirmation on accession number P77072

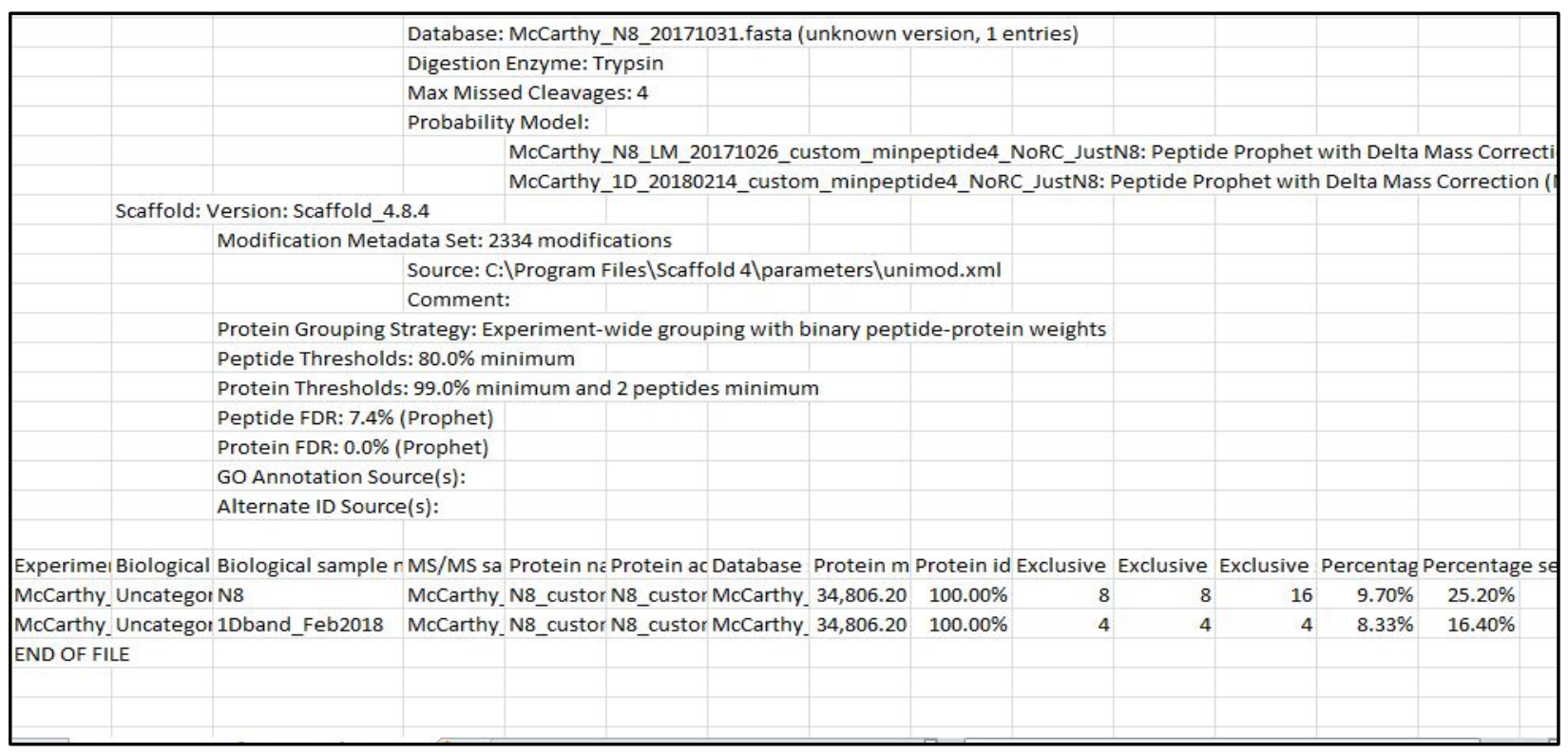


Excerpt from protein report indicating $100 \%$ id for both replicates

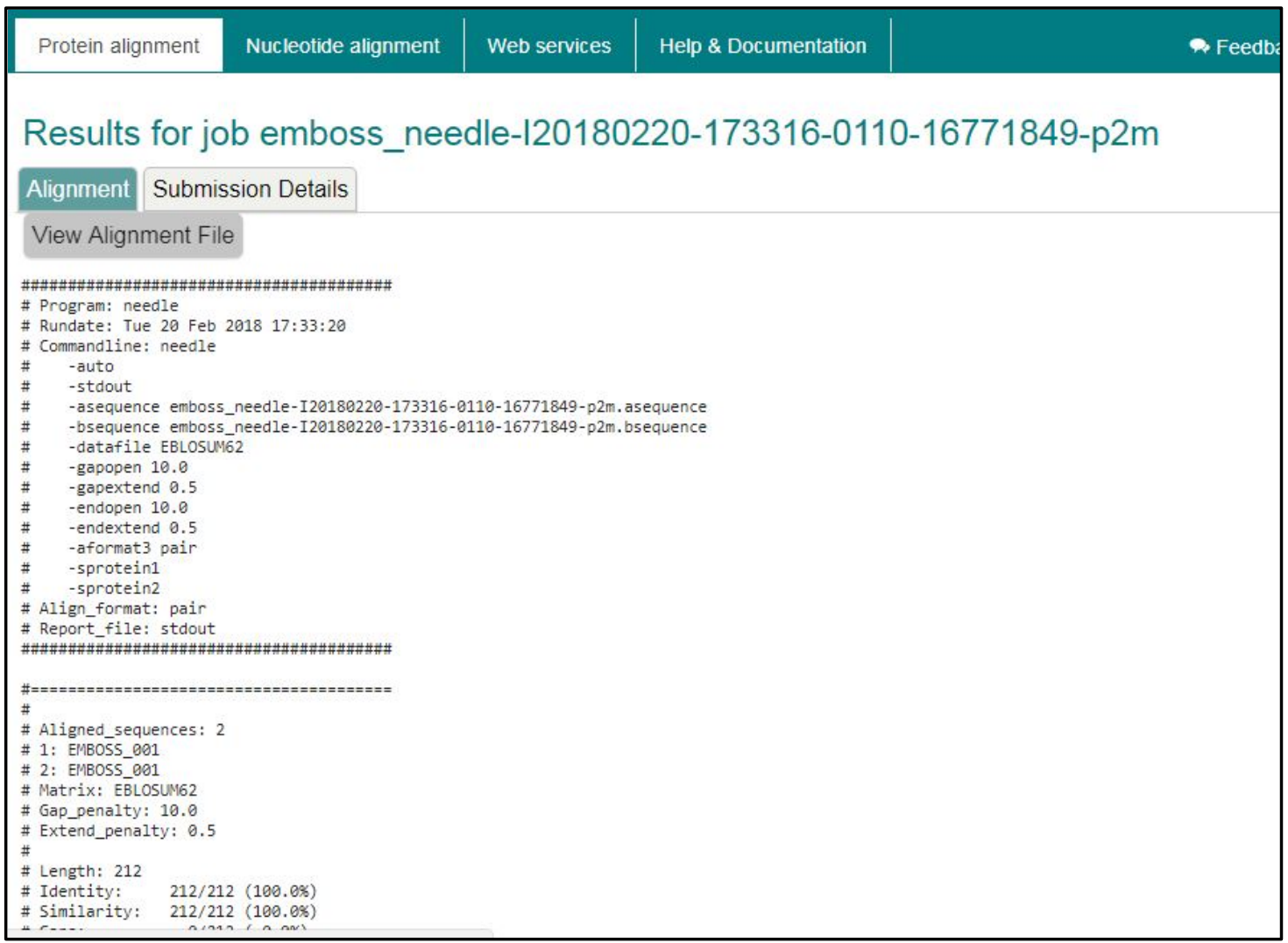

Emboss Needle pairwise sequence results P77072 amino seq vs designed construct (100\% match 212 residues).

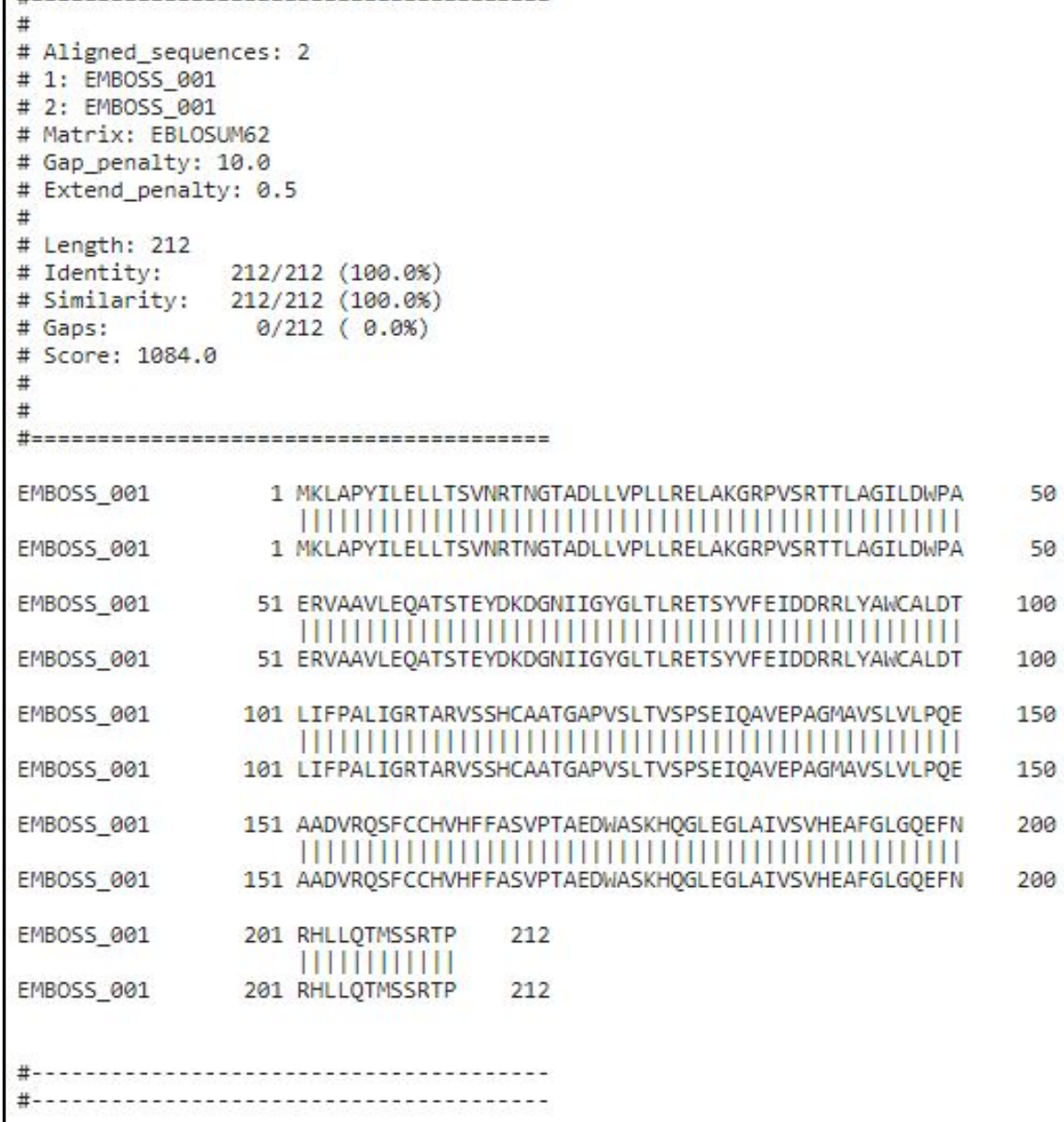


Emboss Needle pairwise sequence results P77072 amino sequence vs designed construct confirming mass spec id match $100 \%$.

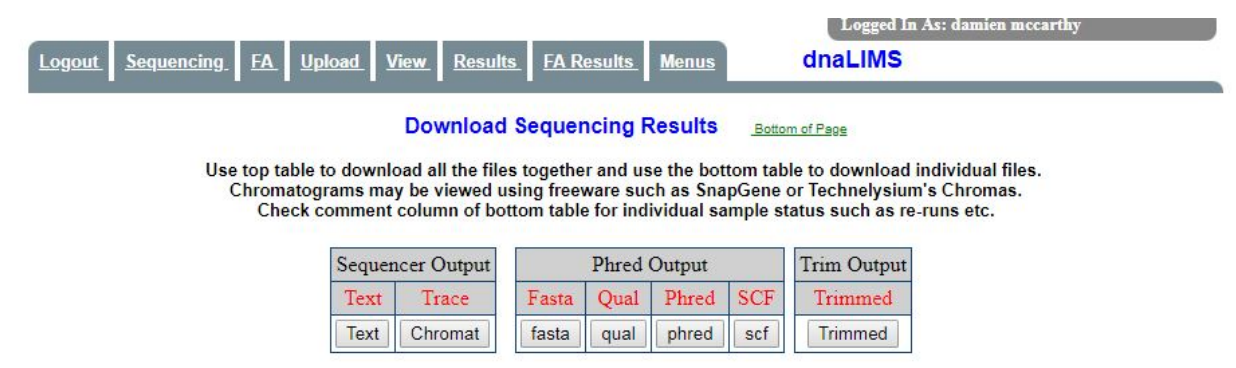

To download individual files:

Mac: Hold down Control Key, Click Mouse. Select Save Linked File As...

PC: Right Mouse Click, Save Link As...

Plate Number: 12398

Rows in grey are checked in to be rerun.

\begin{tabular}{|c|c|c|c|c|c|c|c|c|c|c|c|c|c|c|}
\hline \multicolumn{15}{|c|}{ Rows in grey are checked in to be rerun. } \\
\hline Order & Req\# & Download & View & Seqld & WID & Sample & Primer & Investigator & UID & Date & Phred Q20 & Trimmed & Edited & Comments \\
\hline 26404 & 873367 & $\begin{array}{c}\text { Text } \\
\text { Chromat } \\
\end{array}$ & View Text & $12398-5$ & E1 & 1 & Invalid & mccarthy,damien & 2805 & May 162017 & $\begin{array}{l}\text { phd qual } 777 \\
\text { fasta scf }\end{array}$ & fasta & & Results Available \\
\hline 26404 & 873368 & \begin{tabular}{c|} 
Text \\
Chromat \\
\end{tabular} & View Text & $12398-6$ & F1 & 2 & Invalid & mccarthy,damien & 2805 & May 162017 & $\begin{array}{l}\text { phd qual } 624 \\
\text { fasta scf }\end{array}$ & fasta & & Results Available \\
\hline 26404 & 873369 & $\begin{array}{c}\text { Text } \\
\text { Chromat } \\
\end{array}$ & View Text & $12398-7$ & G1 & 3 & Invalid & mccarthy,damien & 2805 & May 162017 & $\begin{array}{l}\text { phd qual } 727 \\
\text { fasta scf }\end{array}$ & fasta & & Results Available \\
\hline 26404 & 873370 & $\begin{array}{c}\text { Text } \\
\text { Chromat } \\
\end{array}$ & View Text & $12398-8$ & H1 & 4 & Invalid & mccarthy,damien & 2805 & May 162017 & $\begin{array}{l}\text { phd qual } 778 \\
\text { fasta scf }\end{array}$ & fasta & & Results Available \\
\hline cs & 873375 & $\begin{array}{c}\text { Text } \\
\text { Chromat }\end{array}$ & View Text & $12398-83$ & C11 & pGem & CP1 & osborne,craig & $1437 \mid$ & May 172017 & $\begin{array}{l}\text { phd qual } 765 \\
\text { fasta } \underline{\text { scf }}\end{array}$ & fasta & & cs \\
\hline
\end{tabular}

There are 5 samples.

Genomic centre results

GTGCATGCAAGGAGATGGCGCCCAACAGTCCCCCGGCCACGGGGCCTGCCACCATACCCACGCCGAAAC AAGCGCTCATGAGCCCGAAGTGGCGAGCCCGATCTTCCCCATCGGTGATGTCGGCGATATAGGCGCCAGCA ACCGCACCTGTGGCGCCGGTGATGCCGGCCACGATGCGTCCGGCGTAGAGGATCGAGATCTCGATCCCGCG AAATTAATACGACTCACTATAGGGGAATTGTGAGCGGATAACAATTCCCCTCTAGAAATAATTTTGTTTAAC TTTAAGAAGGAGATATACATATGCGGGGTTCTCATCATCATCATCATCATGGTATGGCTAGCATGACTGGTG GACAGCAAATGGGTCGGGATCTGTACGACGATGACGATAAGGATCATCCCTTCACCATGGTTAAAACCCAG GCAACCAGCCGTGAAGAACCGCCTCGTCTGCCGAGCAAACATCGTCCGGGTGTGAAAACACAGGCCACCTC ACGCGAAGAACCTCCACGCCTGCCTTCAAAACACCGTCCTGGCGTAAAAACGCAGGCGACAAGTCGTGAG GAACCTCCGCGTTTACCGTCTAAACATAGACCTGGGGTGAAAACCCAGACCGCAAGCAAACTGGCACCGTA TATTCTGGAACTGCTGACCAGCGTTAATCGTACCAATGGCACAGCCGATCTGCTGGTTCCGCTGCTGCGTGA ACTGGCAAAACGTCGTCCGGGTTAGCCGTACCACACTGGCAGTATTCTGGATTGGCCTGCAGACGTGTTGC AG 